\title{
Sociologia y preconsciente freudiano: El nivel latente en el análisis del discurso ideológico
}

\section{Sociology and freudian preconscious: latent level in the ideological discourse analysis}

\author{
Marc Barbeta Viñas \\ Universidad Autonoma de Barcelona \\ marc.barbeta@gmail.com (ESPAÑA)
}

Recibido: 16.062014

Aceptado: 27.10.2014

\section{RESUMEN}

En este trabajo se propone una aproximación a la noción freudiana de preconsciente, con el objetivo de fundamentar teórico-metodológicamente el nivel latente del análisis sociológico del discurso. Recuperando algunas de las aportaciones realizadas por los sociólogos Ángel de Lucas y Alfonso Ortí, se desarrolla la hipótesis de la génesis social y colectiva del preconsciente, y su constitución por medio del lenguaje y de sus usos sociales. Se defiende que esta concepción del preconsciente plantea un nivel de análisis pertinente y relevante para la sociología, y más específicamente para el análisis sociológico de las ideologías, estableciendo una estrategia de análisis sobre los contenidos preconscientes de los discursos ideológicos. En línea con algunas escuelas de análisis del discurso, se presentan algunas claves metodológicas orientadas a la práctica del análisis del nivel latente de los discursos sociales.

\section{PALABRAS CLAVE}

Preconsciente, análisis discurso, ideologías, psicoanálisis, sociología, nivel latente, lenguaje. 


\begin{abstract}
This paper is proposed an approach to the freudian notion of preconscious, in order to substantiate theoretical and methodologically the latent level of sociological discourse analysis. Recovering some of the contributions made by sociologists Ángel de Lucas and Alfonso Ortí, the hypothesis of the genesis of collective preconscious and its constitution through language and its social uses is developed. We argue that this social conception of preconscious poses a pertinent and relevant level analysis to sociology, and more specifically for the sociological analysis of ideologies, establishing a strategy analysis of preconscious contents of ideological discourses. Some key methodological practice-oriented analysis of the latent level of social discourse is presented, online with some schools of discourse analysis.
\end{abstract}

\title{
KEY WORDS
}

Preconscious, discourse analysis, ideologies, psychoanalysis, sociology, latent level language.

\section{INTRODUCCIÓN}

Si como afirmaba Peter Berger (1963) la sociología se define como una práctica de desenmascaramiento de los sistemas sociales, es comprensible que algunas corrientes de análisis cualitativo, y particularmente aquellas más próximas al análisis sociológico del discurso, hayan puesto de manifiesto la necesidad de atender a los elementos menos patentes, evidentes o perceptibles de los discursos en el análisis de su sentido. Un planteamiento así no debe entenderse como la tarea de mostrar lo supuestamente oculto de los discursos, sino más bien de enfrentarse a ellos desde una posición de cierta sospecha. El desarrollo de este enfoque debería manejar un modelo teórico-metodológico que permita comprender la relación entre los discursos verbales objeto de análisis y los actores sociales, es decir, los sujetos protagonistas de la enunciación. Y a su vez, enfrentar la dificultad de articular en una misma concepción, los aspectos objetivos y subjetivos de las condiciones de la producción discursiva. Por una parte, los componentes externos a los sujetos, como son las posiciones sociales (en sentido amplio), que responden a los contextos de la producción discursiva. Por otra, los componentes más subjetivos, asociados a la dimensión biográficapersonal y afectiva, que sin ser siempre totalmente conscientes también ejercen su influencia en la configuración de los sentidos con los que los actores sociales significan sus vivencias. Además, si el compromiso del análisis sociológico es abordar los fenómenos que se pretenden investigar fundamentalmente desde lo social y colectivo, dicho planteamiento debe permitir acercarse a los discursos no tanto desde un plano psicológico estrictamente individual, sino como 
producto social (lo que no quiere decir que no puedan mediar en este proceso componentes psicológicos o de otro tipo).

Siguiendo esta perspectiva, los sociólogos Ángel de Lucas y Alfonso Ortí han situado la noción de preconsciente elaborada por Sigmund Freud en un lugar central de su análisis sociológico del discurso. Estos autores han defendido la hipótesis del carácter social y colectivo de dicho estrato de la personalidad. Así, inscriben en el preconsciente las formaciones simbólicas e ideológicas que configuran los discursos sociales, coincidiendo en esta cuestión con otros autores más o menos próximos a sus planteamientos. Estas ideas han sido expuestas oralmente en su actividad docente y apuntadas en algunos trabajos, pero no encontramos ninguna publicación en la que las hayan desarrollado de manera completa y sistemática. ${ }^{1}$

Las aportaciones de los citados autores constituyen un punto de partida para el presente trabajo. En éste pretendemos, como primer objetivo, recuperar y desarrollar la hipótesis del carácter social del preconsciente freudiano, con el fin de contribuir a fundamentar el trabajo de análisis sociológico del discurso. Más concretamente, el nivel de análisis dirigido a captar el sentido preconsciente de las formaciones ideológicas. Como segundo objetivo, nos proponemos caracterizar las dimensiones más relevantes del nivel preconsciente-latente del discurso, así como esbozar algunas indicaciones y apuntes metodológicos básicos que tienen como fin contextualizar y orientar su análisis.

El trabajo desarrolla la noción de preconsciente en Freud; a continuación, relaciona las formaciones ideológicas con este mismo sistema; seguidamente establece una correspondencia entre lo preconsciente y el nivel latente del análisis del discurso para después plantear sus características y algunas pautas generales para su análisis; finaliza con unas conclusiones.

\section{EL LUGAR DEL LENGUAJE EN LA TEORÍA PSICOANALÍTICA DE FREUD: EL PRECONSCIENTE}

Es bien sabido que el objetivo principal del psicoanálisis es el estudio del inconsciente, igual que también lo es que el lenguaje, ya desde la idea del talking cure [cura por la palabra], ocupa un lugar central en la teoría y la práctica psicoanalíticas. De hecho, la relación entre psicoanálisis y lenguaje ha suscitado un importante debate dentro del mismo modelo psicoanalítico. ${ }^{2}$ Sin embargo,

${ }^{1}$ Los trabajos de los citados sociólogos nos sirven como guías para el planteamiento general de buena parte de los aspectos que aquí se desarrollan. La reconstrucción de estas ideas, en parte, se va a apoyar no solo en algunos de los trabajos publicados por de Lucas y Ortí donde aparecen algunos aspectos relativos a dichas cuestiones, sino también en dos transcripciones de las enseñanzas de Ángel de Lucas, una de las cuales, por fortuna, ha sido recientemente recogida y publicada en Arribas (2013). No hace falta decir que, aunque algunas de estas hipótesis fueron expresadas por los citados autores, entre otros, los errores, malas interpretaciones o cualquier objeción que se pueda realizar al presente trabajo, son solo imputables a quién escribe estas líneas. Puede ser de interés para el lector el artículo homenaje de Ortí (2012) a Ángel de Lucas, recientemente fallecido.

${ }_{2}$ El lenguaje en el modelo psicoanalítico ha sido tradicionalmente un motivo de debate, ya no 
aquí perseguimos el objetivo, más modesto, de situar el lenguaje en la teoría psicoanalítica de Freud, como primer paso hacia la hipótesis, formulada por Ángel de Lucas (1990), acerca de la génesis colectiva y social del preconsciente. Idea que va estrechamente ligada a otra hipótesis sobre la configuración por el lenguaje del preconsciente, que también han defendido autores como Ricoeur (1974: 209). Para su desarrollo nos centraremos básicamente, como ha hecho de Lucas, en la exposición de la primera tópica, por dos razones: la primera, porqué es donde Freud dedica mayor atención al preconsciente (sin contradicciones, en lo fundamental, con la segunda tópica); la segunda, más importante, porqué dibuja un modelo formal susceptible de ser aplicado metodológicamente con fines sociológicos. Veamos los elementos básicos del recorrido de Freud en este asunto.

Con la Interpretación de los sueños Freud traslada buena parte de las hipótesis que había desarrollado en su etapa como neurólogo al terreno de la psicología. Antes de la redacción de la obra inaugural del psicoanálisis dedica muchos años de su vida a la investigación y a la atención clínica de pacientes. En este marco empieza a asentar las bases de una teoría del aparato psíquico, que va definiéndose como organizado y en proceso de estratificación. En la Carta 52 a Fliess (1896), Freud dibuja un primer esquema basado en una triple transcripción de las experiencias de la vida en el aparato psíquico, que será retomado en obras posteriores.

El desarrollo de este primer esquema se produce con la elaboración de la primera tópica, expuesta parcialmente en el capítulo VII de la Interpretación de los sueños, donde se avanza en la comprensión del preconsciente. Aquí Freud (1900) concibe el aparato psíquico dividido en instancias con intereses distintos. El aparato posee una orientación, y se define por dos extremos, desde donde los procesos psíquicos transcurren del uno al otro. El extremo perceptivo, por donde recibe los estímulos, sea del mundo exterior, sea del interior, que buscan la descarga (aun no habla de pulsiones), a través del extremo motor. Freud se apoya en el principio de Fechner-siguiendo el consenso científico de la época- para establecer el 'principio de inercia' del aparato psíquico, según el cual todo aumento de excitación o tensión es sentida como displacer, por lo que el mismo aparato tiende a la descarga para ser aliviado. Y en relación con ello, utiliza el 'principio de constancia' para explicar que en el interior del aparato psíquico existe un potencial de energía y que solo es el exceso lo que tiene que descargarse para evitar el displacer: se busca el mínimo nivel de excitación posible. Freud los pone en relación con su principio de placer/displacer, según el cual la finalidad de la actividad psíquica sería la de evitar el displacer y procurar el placer (Laplanche y Pontalis, 1967: 296-299). Freud formula la hipótesis de un tipo ideal que caracteriza la prehistoria del sujeto: el aparato psíquico en su momento inicial. Es decir, apela a una supuesta situación originaria en la que

solamente a partir de la obra de Freud, sino de los autores llamados post-freudianos, especialmente con la obra de Lacan. 
la energía es libre ${ }^{3}$ y tiende a ser descargada inmediatamente y por el camino más corto. Entiende que es a partir de esta situación hipotética -o mítica- que el aparato psíquico va constituyéndose a lo largo del desarrollo del sujeto.

Las primeras diferenciaciones que sufre el aparato en el proceso de desarrollo, Freud las establece en relación con los llamados sistemas mnémicos, constituidos por las huellas de las experiencias vividas y la recepción de percepciones. ${ }^{4}$ Como el sistema perceptivo carece de capacidad de almacenamiento (debe quedar 'libre' para ejercer la función perceptiva), estas huellas deben almacenarse, con el tiempo, en dichos sistemas, generándose así la función de la memoria. Un primer sistema conserva las huellas de las impresiones en bruto; estas huellas, no obstante, no solo se corresponden con el contenido positivo de las experiencias, sino que se entrelazan mutuamente, de aquí que un segundo sistema conserva las relaciones más sencillas entre percepciones, las asociaciones de simultaneidad (por ejemplo, la sensación de hambre y el pecho de la madre). En sistemas sucesivos se conservan las relaciones más complejas entre percepciones: de semejanza, de contraste, de relaciones entre relaciones, causalidad, etc. El conjunto de estos sistemas, cada vez de mayor complejidad, se van constituyendo a lo largo de la biografía del sujeto, haciendo más complejo el proceso de descarga energética. Esto incluye no solo las asociaciones primitivas y la adquisición del lenguaje, sino también todo el proceso de aprendizaje en sus distintas fases. ${ }^{5}$ En la medida en que avanza el desarrollo, las excitaciones, los estímulos recibidos por la percepción ya no recorren el camino más corto hacia el extremo motor y su descarga, como en la situación originaria, sino que el recorrido va siendo condicionado por las huellas mnémicas. Los sistemas mnémicos forman la base de las asociaciones psíquicas, lo que supone que las huellas y los recuerdos se difunden en un orden. Estas huellas se reactivan cuando son cargadas de excitación -con la energía psíquica de las pulsiones-, pero sus relaciones dependen de la forma en que fueron inscritas. ${ }^{6}$ Siendo los sistemas mnémicos el resultado de la biografía del

${ }^{3}$ Es el factor cuantitativo de las operaciones psíquicas en que la energía fluiría libremente hacia la descarga del modo más rápido posible. Este término se corresponde con el proceso primario y se opone al de energía ligada, donde la descarga se halla controlada y retardada (Laplanche y Pontalis, 1967: 115-118)

${ }^{4}$ No son pocos los autores que, desde la neuropsicología, la biología y disciplinas afines han visto coincidencias, similitudes y aproximaciones con las ideas de Freud acerca de sus planteamientos de los sistemas mnémicos, entre otros aspectos. Se dice que las huellas mnémicas actualmente pueden leerse como inscripción neurobiológica de la experiencia sensorial y la búsqueda intencional y psicológica de la experiencia primaria (deseo). Por ejemplo, se habla de engramas, en lugar de huellas, para referirse a las interconexiones neuronales. Véase a este respecto: Solms (2004), Damasio (1999), Kandel (1999), y Coderch (2006). Para un diálogo con la psicología cognitiva, véase Glymour (1991) y Erdeliy (1987).

${ }_{5}$ Distintos autores han puesto en relación las hipótesis psicoanalíticas con las aportaciones de la psicología de Piaget. Anzieu (1981) destaca el anclaje corporal del habla y el lenguaje. Furth (1990) elabora una teoría del proceso de simbolización, articulando la formación del 'objeto permanente' piagetiana con la libido freudiana como factor motivacional.

${ }^{6}$ Aquí se impone el término de facilitación, que Freud elabora en sus trabajos neurológicos: la energía psíquica necesita vencer una cierta resistencia para pasar de una neurona a otra, pero una 
sujeto, constituyen la base del carácter del mismo (Freud, 1900: 533). ${ }^{7}$

La función de la memoria supone la actualización de determinadas huellas mnémicas, habiendo algunas que no es posible actualizar: a esas Freud las sitúa en el inconsciente. Se trata de aquellas huellas que nunca podrán ser conscientes, especialmente aquellas inscritas tempranamente en la biografía del sujeto. Las huellas actualizadas voluntariamente devienen, en su conjunto, en el consciente; y entre los dos sistemas anteriores, Freud sitúa al preconsciente, que ejerce de barrera. La hipótesis de Freud es que todo proceso psíquico -incluyendo, obviamente, el sueño, del que afirma que es una realización de deseos- parte de la excitación energética producida en el inconsciente, y que en su camino hacia la descarga en la consciencia, se encuentra con el preconsciente actuando como barrera que regula el acceso al extremo motor: como dice Freud (1900: 534), 'es el sistema que tiene las llaves de la motilidad voluntaria'. En ocasiones el preconsciente impide el paso de la excitación hacia la consciencia y toma un camino de 'reflujo' propagándose hacia la percepción; se trata de un proceso de regresión que explicaría la figurabilidad de los sueños (Freud, 1900: 536542). Pero el preconsciente, como expone de Lucas (1998: 149, 150), a veces facilita el paso de lo inconsciente modificándolo, imponiéndole unos requisitos para su manifestación en la consciencia. Se trata, en el caso del sueño, del paso del llamado contenido latente al contenido manifiesto, que por el trabajo del sueño (con las herramientas de condensación, desplazamiento, figurabilidad), el preconsciente modificaría aquello que viene del inconsciente de forma que pueda admitirse en la consciencia. Debemos subrayar que esto no solamente sería válido para los sueños, sino como apuntan Laplanche y Pontalis (1967: 82), para toda producción verbalizada, también -añadimos- un discurso social. Se observa pues, que Freud sitúa la barrera de la represión entre el sistema preconsciente y el inconsciente, siendo los contenidos preconscientes susceptibles de pasar a la consciencia dadas determinadas condiciones. La actividad imaginaria consciente o preconsciente, orientada a la búsqueda de experiencias satisfactorias anteriores

vez conseguido, se dice que la conexión entre esas neuronas es una vía facilitada permanente. La excitación tiende a pasar por las vías facilitadas, antes que por las que no lo están

7 Perspectivas psicoanalíticas actuales han abordado estas cuestiones desde la noción de las relaciones de objeto, donde lo fundamental no es tanto la descarga como la vinculación con el objeto, y donde se aceptan modelos de inconsciente y memoria no dinámicos. A través de la neurociencia y la psicología cognitiva hoy se habla de un inconsciente de procedimiento que difiere del reprimido, descubierto por Freud. En el primero, habría las formas de memoria procedimental, que incluye la memoria de configuración que nos permite reconocer palabras, sonidos previamente percibidos, etc., la memoria emocional, entre otras. Se trata de un inconsciente no declarativo, no puede 'traducirse' o formularse en imágenes o palabras, y actúa en hábitos, acciones rutinarias, habilidades adquiridas e incluso en respuestas o esquemas emocionales. Tanto psicoanálisis como neurociencia han acordado la existencia de ambos inconscientes (dinámico y procedimental), incluso se habla de la articulación y trasvase entre los dos (Coderch, 2006). Podríamos plantearnos en qué media el preconsciente es el lugar donde se dan más puntos de unión entre las llamas formas de conocimiento explícito y implícito, dado el proceso primario evolucionado que según se conoce hoy, en él se desarrolla. Justamente este proceso psíquico se halla involucrado con las interacciones del sujeto y el mundo que le rodea, tanto humano y social como material (Coderch y Codosero, 2013). .

EMPIRIA. Revista de Metodología de Ciencias Sociales. N. ${ }^{\circ}$ 31, mayo-agosto, 2015, pp. 97-129. ISSN: 1139-5737, DOI/empiria.31.2015.14539 
marcadas en las huellas, tiene que adaptarse a la realidad exterior y a los límites que ésta le impone. ${ }^{8}$

Los escritos de Metapsicología proporcionan los elementos clave que nos permiten sostener la hipótesis acerca del lugar del lenguaje. Freud (1915: 183186) establece algunas distinciones importantes entre sistemas, por ejemplo, relativas al carácter impulsor del inconsciente, donde no existe la negación, en contraste con el carácter reactivo e inhibidor del preconsciente; el carácter atemporal del inconsciente y la relación con el tiempo exterior del preconsciente. En los contenidos es donde probablemente se produce un mayor avance, así como en la definición de sus relaciones.

Freud modifica la tesis anterior de las inscripciones en diferentes lugares del aparato para establecer las diferencias entre el contenido de los distintos sistemas. Si el inconsciente es el lugar de los contenidos reprimidos, en el preconsciente habría elementos derivados de la percepción, y además, la mediación de la vida pulsional del inconsciente (Freud, 1915: 191). El inconsciente estaría formado por representaciones-cosa, que se corresponden con la investidura de una huella mnémica o aquellas huellas alejadas, derivadas de la representación-cosa; mientras que preconsciente y consciente, se caracterizarían por la conexión entre representaciones-cosa y representacionespalabra, que incluyen la conexión entre las huellas investidas energéticamente y la representación verbal correspondiente. Freud observa que ambos tipos de representaciones provienen de la percepción sensorial, lo que parece indicar que se inscriben en el aparato psíquico desde su relación con el exterior, creando así la posibilidad de entender la creación del preconsciente a través del lenguaje. En este sentido, Freud (1915: 198) afirma: "el sistema preconsciente nace cuando esa representación-cosa es sobreinvestida por el enlace con las representaciones-palabra que les corresponden. Tales sobreinvestiduras podemos conjeturar, son las que producen una organización psíquica más alta y posibilitan el relevo del proceso primario al proceso secundario que gobierna en el interior del preconsciente'. Recientemente se ha hablado de un 'proceso primario evolucionado' como lo propio del preconsciente, en el que se articulan lo afectivo, las imágenes y aspectos del lenguaje, fundado sobre las percepciones y las interacciones que los sujetos mantienen con el mundo material (Coderch y Codosero, 2013: 8).

La vinculación entre representaciones-cosa y palabra permiten a las representaciones-cosa devenir conscientes, acceder a la consciencia, mediante la ligadura con las huellas verbales, las impresiones que dejan las palabras al ser oídas. Las representaciones-palabra, de este modo, nos permitirían ver el lenguaje como un sistema de representaciones dirigido por la gramática e indispensable para el procesamiento y la utilización por los sujetos de las

${ }^{8}$ En Freud la represión no niega la realización de deseos, sino que más bien administra deseos de sentido opuesto. Por otra parte, vemos que Freud utiliza en los textos de la primera tópica el preconsciente como substantivo, para referirse a un sistema distinto al inconsciente, como adjetivo para calificar los contenidos y funciones del mismo, i finalmente de forma descriptiva. .

EMPIRIA. Revista de Metodología de Ciencias Sociales. N. o 31, mayo-agosto, 2015, pp. 97-129. ISSN: 1139-5737, DOI/empiria.31.2015.14539 
informaciones recibidas (Sperber y Wilson, 1995). ${ }^{9}$ En el contexto de un estímulo pulsional, con la represión el afecto queda 'liberado' para vincularse a una representación admisible para la consciencia: a través del lenguaje, y no en pocas ocasiones mediante la contrainvestidura, se configuran representaciones sustitutivas de lo inconsciente, ahorrando energía a la represión. De este modo, el lenguaje tendría una función de descarga, aunque se trataría de una descarga 'controlada', dado que en el preconsciente las representaciones-palabra están organizadas, siguen la estructura del lenguaje tal y como ha sido incorporado. Tal vinculación puede entenderse como el resultado de las experiencias vividas por los sujetos, y por lo tanto, el modo en que el lenguaje fija estructuras o formas organizadas de descarga en los mismos.

En este camino hacia la descarga a través del preconsciente, parecen mediar también los mecanismos de la condensación y el desplazamiento. Algunos autores los han caracterizado a partir de un doble nivel energético-afectivo y perceptivo-cognitivo (Lorenzer, 1970: 65-76), lo que permite situarlos en este mismo sistema psíquico. ${ }^{10}$ Así mismo, Ricoeur (1978: 84-89) propone una lectura lingüística de estos mecanismos, lo que sugiere una aproximación desde lo preconsciente; también Conde (2009: 233 y ss.) enfatiza su análisis en los discursos sociales más desde el preconsciente colectivo que del inconsciente individual.

Igual que afirmaba de Saussure (1916), podemos decir que el lenguaje tiene una doble dimensión interrelacionada: individual y colectiva; pero a diferencia de él y siguiendo a Freud, el lenguaje no se presentaría en los sujetos como algo absolutamente inmotivado o arbitrario, sino vinculado a lo afectivo, vehiculando la energía del aparato psíquico hacia su descarga. ${ }^{11} \mathrm{Si}$ además consideramos la estructura social como contexto de referencia, los sujetos pertenecen y se socializan en determinados grupos sociales. Y así, podemos convenir que se apropian el sistema de la lengua y lo actualizan colectivamente en hablas sociales distintas, tal y como lo muestra Hjelmslev (1968) con el análisis de los usos del lenguaje, Mijail Bajtin (1982) con el estudio de los géneros discursivos, o Rossi-Landi (1980) con las nociones de habla común y lenguaje colectivo, por las que se explican los usos lingüísticos de los grupos, como parte de la misma práctica social. En el marco del preconsciente, más allá de entenderse el lenguaje desde su lógica interna, se constituye desde lo social -posiciones y situaciones sociales diversas-, y se desarrolla en la praxis social, en lo colectivo y común de

\footnotetext{
${ }^{9}$ El nivel preconsciente-latente podría corresponderse con la estructura profunda de Chomsky.

${ }^{10}$ En la segunda tópica el preconsciente queda situado en una parte del Yo y del Superyó y la carga energética parte del Ello. Aquí Freud afirma que si bien lo reprimido es inconsciente, no todo lo inconsciente es reprimido (Freud, 1923).

${ }_{11}$ Podríamos reconocer un cierto continuum entre los signos de la lingüística, entendidos como elementos inmotivados, y los símbolos, como signos polisémicos cargados de afecto. Así Lorenzer (1970) establece diferentes niveles de símbolos, y siguiendo a Sussane Langer diferencia entre símbolos discursivos y presentativos, implicando este último tipo, una mayor carga energética, afectiva. .
} 
los discursos.

En definitiva, esta vinculación entre preconsciente y lenguaje establecida por Freud, nos permite comprender -como sugiere Ángel de Lucas- la naturaleza social del preconsciente, en la medida en que éste se configura con el proceso de socialización de los sujetos, en los acontecimientos biográficos de los mismos y en la situación introductoria del lenguaje, que siempre se suceden en contextos familiares concretos, ubicados en situaciones de clase determinadas (Lorenzer, 1972). No debe confundirse, sin embargo, la perspectiva que aquí desarrollamos con una visión determinista lineal, que entendería una determinación fija y directa de las conductas y los discursos por las huellas mnémicas del pasado. Como bien observaba Freud, éstas se reactualizan en función de las situaciones $\mathrm{y}$ acontecimientos presentes que vive el sujeto, y consiguen evocarse en unos contextos asociativos determinados y en cambio no en otros.

\section{PRECONSCIENTE E IDEOLOGÍAS: LA EFICACIA IDEOLÓGICA}

Esta revisión de la teoría freudiana nos ha permitido desarrollar, en cierta medida, la hipótesis que sitúa la génesis de lo preconsciente en el ámbito social, y concretamente su formación a partir de la adquisición del lenguaje. A continuación nos proponemos vincular el lenguaje, inscrito en el preconsciente, con las formaciones ideológicas y su reproducción en los sujetos y grupos sociales.

Ya el estructuralismo, a través de Althusser (1965), puso en relación de analogía la ideología y el lenguaje, afirmando que es a través de éste por donde tiende a circular la ideología. Sin embargo, la concepción althusseriana sitúa la ideología en el inconsciente freudiano (Eagleton, 1995: 191), la cual deriva hacia un modelo teórico por el que los sujetos estarían absolutamente 'sujetados' por una estructura ideológica general, dominante y omnipresente en las ideologías concretas.

En términos entendemos que algo más realistas, en una primera aproximación podemos establecer que la ideología con el lenguaje puede quedar vinculada en un sentido básico, a partir del principio de expresabilidad. Tal y como afirma Van Dijk (1998) -probablemente adaptando dicho principio del formulado por Searle-, toda ideología puede ser expresada o formulada en el lenguaje natural; y en todo caso, las creencias ideológicas necesitan ser expresables a través de algún tipo de lenguaje o sistema semiótico. Siendo esto cierto, no obstante, Benveniste (1971) sugiere que las ideologías tienen más que ver con los discursos que con el lenguaje, es decir, con los usos del lenguaje y los efectos por ellos creados, que ya hemos visto, se relacionan con lo preconsciente tal y como ha sido incorporado en tanto que modos de uso y esquemas de interacciones verbales.

Los usos ideológicos del lenguaje han sido ampliamente estudiados: desde la 'linguística crítica' (Hodge y Krees, 1979); la teoría de la argumentación de Ducrot (1986); el circulo de Bajtin y el énfasis puesto en el carácter ideológico 
de los signos lingüísticos (Voloshinov, 1929); los trabajos más recientes de Fairclough (1995) y Van Dijk (2003a); o desde una lectura de las relaciones entre el habitus y la producción discursiva (Bourdieu, 1985), ${ }^{12}$ entre otros.

En sociología es ya un tópico que el análisis de los elementos del lenguaje permite un acercamiento a las formaciones ideológicas que los sujetos, de forma colectiva, construyen sobre sus experiencias en los diversos ámbitos sociales (Ibáñez, 1979; Alonso, 1998). Con este propósito el mismo de Lucas (1990) acude a la concepción de ideología de Therborn (1980), definida en términos amplios, multidimensionales y conflictivos, probablemente más adecuados y fecundos para el enfoque sociológico (Alonso, 1998: 117-121). ${ }^{13}$

Para Therborn (1980: 13) la ideología sería un dispositivo para la significación de los procesos sociales, consistiría 'en la constitución y modelación de la forma en que los seres humanos viven sus vidas como actores conscientes y reflexivos en un mundo estructurado y significativo'. La ideología incluiría, desde esta perspectiva, nociones, experiencias, así como doctrinas más elaboradas o sistemas de pensamiento. Para este autor, la ideología jugaría un papel fundamental en la formación de la subjetividad, a través de procesos de 'sometimiento-cualificación'. En estrecha relación con lo mencionado en el epígrafe anterior, el autor establece un vínculo de cierta reciprocidad entre lo que llama personalidad o estructuras de carácter y subjetividad, si bien reconoce la distinción entre ambos conceptos. Los primeros designarían 'los resultados de los procesos psicodinámicos estudiados por el psicoanálisis (...). Estos procesos operan sobre un material -las energías y deseos libidinales de los niños presubjetuales- y a través de unos mecanismos en su mayoría inconscientes', y añadiríamos, preconscientes. Sin embargo, 'La formación de la personalidad' añade Therborn (1980: 13)- 'coincide más o menos en el tiempo con la primera formación de los seres humanos como sujetos, de la cual las interpelaciones ideológicas constituyen una parte fundamental'. De este modo, las formas de subjetividad se constituirían por intersecciones de lo psíquico y lo social. Y así, las ideologías se presentarían como procesos constitutivos de la vida social, con el establecimiento de una relación entro lo psicológico y lo social (Ricoeur, 1989: 54).

Para Therborn (1980: 15, 16), el funcionamiento social por el cual las ideologías someten y cualifican a los sujetos comprende tres formas fundamentales: interpelan sobre lo que existe y no existe, desplegando así una determinada visión del mundo, y con ella, un sentido de identidad propio y del mundo; lo que es bueno, correcto, atractivo y sus contrarios, estructurando así los deseos de los sujetos; lo que es posible e imposible, lo que configura las

\footnotetext{
12 Sobre la teoría de los mercados lingüísticos del autor francés, véase Alonso (2002).

${ }^{13}$ Esta concepción postathusseriana, como se observa, se opone tanto a la visión restringida de la ideología (en tanto que forma errónea de conocimiento en contraposición a la ciencia, el conocimiento real), como a las visiones que solo ven la ideología como mecanismo de integración y regulación total de lo social. Aquí situamos las ideologías, más bien, como visiones del mundo, como procesos sociales conflictivos de significación, absolutamente anclados a la organización social material y sus interacciones.
} 
expectativas, ambiciones, temores o renuncias. Debidamente articuladas, estas formas de interpelación ideológica tienden a generar sujetos concretos que atribuyen significados también concretos a los procesos sociales. Pero como avanzábamos, las ideologías suelen materializarse y culminar en discursos ideológicos, que suponen un modelo generativo de distintos sistemas de representaciones con una misma orientación ideológica (Verón, 1976: 251- 261). Como afirma Alonso (1998: 118), las ideologías se convierten en discursos sobre condiciones concretas a los que se aplican los esquemas genéricos de representaciones ideológicas. El sujeto ideológico, así, se encuentra dentro de estructuras discursivas, lo que nos conduce a referirnos a las posiciones de sujeto en tanto que posiciones discursivas (Laclau y Mouffe, 1985: 196, 197.); en éstas es donde se actualizan y pueden hacerse aprehensibles las ideologías.

Desde la perspectiva de la reproducción de las formaciones ideológicas, el mecanismo por el cual se desplegaría la eficacia ideológica, es decir, la forma como la interpelación ideológica conseguiría estructurar en los sujetos individuales discursos ideológicos, actitudes o pautas específicas de comportamiento, estaría plenamente relacionada con la mediación del preconsciente. Observa Freud (1900: 495) que las formas preconscientes de pensamiento 'se comportan hacia un material perceptible cualquiera de idéntico modo que lo hace esta función hacia el contenido onírico. Le compete poner orden en ese material, establecer relaciones y adecuarlo a la expectativa de una trama inteligible'.

Con este planteamiento podríamos entender que habría dos formas distintas y no excluyentes de recepción de estímulos en el aparato psíquico; dos formas, por tanto, de movilizar las pulsiones. Por una parte, éstas podrían quedar investidas y generar actividad de forma espontánea, desde su relación con el cuerpo, lo somático. Pero por otra parte, las pulsiones podrían movilizarse a partir de estímulos externos, es decir, de acontecimientos que suceden afuera del aparato psíquico, sean hechos o discursos, la impresión creada por los cuales tendría la capacidad de investir determinadas huellas mnémicas, y provocar así un proceso inconsciente; éste, como sabemos, buscará la descarga con el acceso a la consciencia. En este caso, mediante el preconsciente, las huellas mnémicas asociadas con elementos verbales (o representaciones-palabra) serían capaces de movilizar, organizar y adecuar la energía pulsional para que sea descargada a través del discurso. Y como afirma Ángel de Lucas, 'La eficacia de la interpelación depende de su capacidad para ligar, en favor de intereses ideológicos, las pulsiones inconscientes del sujeto, de manera que esta ligadura facilite -y digo facilite en el sentido técnico que este término tiene en la teoría freudiana- una determinada forma de irrupción en la conciencia y la descarga consiguiente en una acción motriz voluntaria. De tal manera que esta ligadura conseguiría, por una parte, el acceso de las pulsiones o deseos inconscientes del sujeto a la conciencia, y consiguientemente una descarga de la pulsión a través de una acción motriz voluntaria (...). La eficacia de las interpelaciones ideológicas, en lo que a la ligadura de las pulsiones inconscientes se refiere, depende muy principalmente de su habilidad para burlar las exigencias de la 
censura psíquica de los sujetos' (de Lucas, 1990: 66).

Entendido así, los discursos tendrían la capacidad de aportar contextos asociativos que posibiliten al preconsciente actualizarse, actuando como mediador entre lo individual y lo colectivo. En el preconsciente se establecerían las condiciones de la producción discursiva, ofreciendo un abanico más o menos limitado de competencias discursivas, además de la posibilidad de 'elección' y cristalización de los discursos. El preconsciente, por tanto, no debería entenderse como una estructura estática, solamente limitante, sino dinámica, en uso y susceptible de operar en la producción discursiva. Su mediación básica seria entre lo profundo, la gramática internalizada socialmente y los contextos histórico-sociales y discursivos. Como nos recuerda Ricoeur (1975: 97), los discursos son una sucesión de elecciones por las cuales ciertos sentidos son elegidos y otros excluidos. Situando estos procesos de elección y creación de sentido en la praxis intersubjetiva, los contextos sociales devienen los condicionantes fundamentales a partir de los cuales el preconsciente proporciona unas vías asociativas, transferenciales ${ }^{14} \mathrm{y}$ unos intereses compartidos, para que los sujetos articulen -asumiendo o rechazando- los discursos ideológicos y sociales.

Dejando de lado la necesaria contextualización socio-estructural e histórica, ${ }^{15}$ sin duda de cabal importancia, aquí tan solo enfatizamos en que la altamente compleja cuestión de la eficacia ideológica tendría éxito, al menos en parte, en un contexto de adecuación de la estructura significativa de las formaciones ideológicas en tanto que formas de resolución imaginaria y preconsciente de conflictos y procesos sociales y personales. La ideologías, como las neurosis estudiadas por Freud, no solo expresarían determinadas problemáticas, sino que serían en sí mismas una estrategia que trata de 'resolver', aunque sea de forma simbólica, determinados conflictos y/o situaciones en que se encuentran sujetos y grupos. Por ello, todo 'discurso ideológico 'opera' sobre los conflictos que intenta negociar (...), al igual que la labor del sueño modifica y transmuta los 'contenidos latentes' del propio sueño' (Eagleton, 1995: 175). No obstante, cabe añadir que no todas las ideologías tendrían las mismas posibilidades de interpelar a todos los sujetos y con los mismos resultados, ni asentarse como formaciones ideológicas en todos los grupos sociales. Más bien, el modo en que se conforma y actualiza el sistema preconsciente, en unas u otras posiciones sociales y ante unas u otras situaciones socio-históricas concretas, serán condicionantes fundamentales para las posibilidades de una interpelación exitosa.

${ }^{14}$ La transferencia, en sentido no restringido, se refiere a la actualización de deseos o posiciones emocionales, intereses o esquemas cognitivos e interaccionales en la relación con los otros y las cosas. Por otra parte, Wilden (1979: 77-84) vincula la facilitación en tanto que capacidad asociativa con la sobdredeterminación a partir de la relación con el contexto, siendo este entorno lo que condiciona la selección de unas asociaciones u otras

${ }^{15}$ Para una distinción de las dimensiones de los procesos de reproducción ideológica, véase Ortí (1988).

EMPIRIA. Revista de Metodología de Ciencias Sociales. N. ${ }^{3}$ 31, mayo-agosto, 2015, pp. 97-129.

ISSN: 1139-5737, DOI/empiria.31.2015.14539 


\section{PRAGMÁTICA DEL ANÁLISIS SOCIOLÓGICO DE LO PRECONSCIENTE: NIVELES DE ANÁLISIS DEL DISCURSO IDEOLÓGICO}

Hemos señalado la relevancia del papel del sistema preconsciente para la eficacia y la reproducción de los discursos ideológicos en sujetos y grupos sociales. De ello se desprende que el sentido de las concepciones sobre el mundo y la experiencia que entraña el concepto de ideología que manejamos, no siempre se presenta de forma inmediata y absolutamente consciente para los actores sociales en su expresión y manifestación discursiva. Como señala Ricoeur (1989: 253), significación y conciencia son separables, pues la primera puede existir sin que sea conscientemente reconocida. Así, en la reproducción de los discursos ideológicos por los sujetos estarían implicados elementos no conscientes que sin embargo, condicionarían la articulación discursiva y especialmente sus efectos de sentido. Esto supone que en los discursos ideológicos podríamos identificar diferentes niveles de sentido, siendo alguno de ellos no directamente identificable si no es a través del trabajo de análisis. Por lo que podríamos afirmar la existencia y la necesidad de considerar distintos niveles de análisis interpretativo de los discursos, especialmente si convenimos en situar una vía de acceso a lo social en aquellas dimensiones no plenamente conscientes, manifiestas y transparentes del lenguaje (Colectivo IOÉ, 2010).

Inspirándose en el trabajo acerca de los sueños de Freud (1900), Alfonso Ortí (1993) propone una triple correspondencia metodológica entre niveles de análisis del discurso, niveles de sentido (o significación) de los discursos, y niveles de consciencia de la primera tópica freudiana.

- El nivel manifiesto, que en un discurso respondería a lo dicho, al contenido positivo y explícito, discernible de manera directa; se trataría del enunciado literal, aparente del discurso. El lenguaje se presentaría como algo transparente, el sentido del contenido se encontraría sin equívocos en el texto, considerando la dimensión referencial o denotativa del mismo (Guiraud, 1971: 12). Este nivel estaría proferido por los sujetos hablantes de forma consciente, en la medida en que la significación del mismo es conocida y expresada de forma abierta y voluntaria por los sujetos. Aquí sería posible extraer el significado de lo expresado (Ortí, 1986), pero la significación residiría únicamente en el individuo, preexistiendo a las constricciones sociales. En este nivel, el análisis de la significación discursiva designaría el componente semántico de la comunicación (Ibáñez, 1985a; Ortí, 1994: 78), refiriendo el análisis al mismo nivel manifiesto (Conde, 2009: 56).

- El nivel latente relativo a las formaciones significativas que, en cuanto que ideológicas, responden a orientaciones vinculadas a valores, creencias, intereses y/o deseos. En el discurso se presenta en proposiciones significativas y manifestativas (Deleuze, 1969: 39 y ss.). Sin embargo, 
lo latente no es siempre directamente discernible por no ser literal o positivo, sino que estaría relacionado con el contenido que subyace lo comunicado en el discurso; es aquello que abre el discurso a sentidos posibles y no conscientes para sus productores (Ricoeur, 1995: 100). Lo latente a veces es lo encubierto, lo velado, lo no buscado o reconocido conscientemente (Giddens, 1989: 791), o incluso lo no dicho pero implicado en aquello que sí ha sido afirmado. ${ }^{16}$ Ángel de Lucas (1997: 4) se refiere a lo latente de un discurso ideológico como 'aquellas cosas no dichas pero que es necesario afirmarlas para que lo dicho tenga coherencia'; tienen que ser 'aceptadas para que el discurso se sostenga'. Aquí el lenguaje no termina en lo evidente, sino que considera las dimensiones dialógica, conativa y metalingüística (Guiraud, 1972: 1315; Voloshinov, 1929). Este segundo nivel estaría proferido de forma preconsciente por los sujetos hablantes (y construido por el investigador a partir de lo dicho preconscientemente), ${ }^{17}$ en la medida en que su sentido no se expresa de forma directamente voluntaria y literal, sino que requiere un trabajo de desciframiento y reconstrucción. Aquí el sentido está sujeto a condicionantes extralingüísticos: sociales, ideológicos, afectivos, etc. Las posibilidades de análisis alcanzan las actitudes, formas de pre-conducta relativamente estables, y los discursos ideológicos, como estructuras subyacentes de sentido (Ortí, 1986), con sus entrañas afectivas más o menos conscientes. El análisis del sentido designa el componente pragmático de la comunicación (Ibáñez, 1985a; Ortí, 1994: 79), lo que refiere el análisis al nivel latente (Conde, 2009: 56).

- El nivel profundo, relativo a las fuerzas motoras, presiones, deseos o intenciones no reconocidas de los procesos motivacionales, que se proyectan valorativa y afectivamente en los discursos. Se consideran fundamentalmente las informaciones manifestativas (Deleuze, 1969: 39) o emotivas del lenguaje (Guiraud, 1971: 12). Este tercer nivel seria inconsciente por los sujetos hablantes, en la medida en que su sentido

${ }^{16}$ Respecto a la crítica de las dimensiones del discurso manifiesta y latente de Martín Criado (1998: 69), señalamos que: a) no necesariamente debe interpretarse lo manifiesto como falso y lo latente como verdadero, sino como planos distintos de significación o sentido. Ya Ricoeur (1975) habla de despliegue de niveles de significación. b) Está fuera de duda que en un discurso pueden encontrarse planos del mismo que no sean reconocidos conscientemente por parte de los sujetos del mismo, como de hecho el autor reconoce en términos bourdierianos al referirse a los esquemas prácticos no conscientes, más o menos cercanos a lo que aquí defendemos como lo preconsciente. c) Nada más lejos de la arrogancia, en psicoanálisis buena parte de la verificación de las hipótesis interpretativas del psicoanalista pasan por la recepción, a través de la experiencia, del analizando. Es éste quién 'tiene la última palabra' sobre la veracidad de las hipótesis realizadas, y de hecho, el éxito terapéutico depende en buena medida de ello, no de la 'imposición' meramente intelectual del analista, como a veces se pretende. .

17 Aquí el 'discurso' sería una construcción teórica realizada por el investigador a partir del 'texto', correspondiente a la literalidad de lo dicho, que tiende a objetivarse y materializarse en una transcripción.

EMPIRIA. Revista de Metodología de Ciencias Sociales. N. ${ }^{\circ}$ 31, mayo-agosto, 2015, pp. 97-129. ISSN: 1139-5737, DOI/empiria.31.2015.14539 
es desconocido por los mismos, pero cuya interpretación es posible a partir de su expresión sintomática en proyecciones afectivas, fallos en el discurso, bloqueos en el discurso racional, etc. También aquí el sentido obedece fundamentalmente a procesos extralingüísticos, si bien es el lenguaje quien los simboliza y nos proporciona las 'noticias' de lo profundo. La aproximación es necesariamente hermenéutica.

Tabla 1. Articulación de la primera tópica freudiana con algunas dimensiones del análisis del discurso

\begin{tabular}{|c|l|c|l|}
\hline $\begin{array}{c}\text { Niveles de } \\
\text { consciencia: }\end{array}$ & \multicolumn{1}{|c|}{$\begin{array}{c}\text { Representantes } \\
\text { psíquicos }\end{array}$} & $\begin{array}{c}\text { Niveles de } \\
\text { análisis }\end{array}$ & Categorías analíticas \\
\hline Consciente & $\begin{array}{l}\text { Consciencia: } \\
\text { representaciones cosa y } \\
\text { palabra. }\end{array}$ & Manifiesto & $\begin{array}{l}\text { Opiniones, verbalizaciones } \\
\text { sobre hechos. }\end{array}$ \\
\hline Preconsciente & $\begin{array}{l}\text { Lugar del lenguaje } \\
\text { representaciones cosa y } \\
\text { palabra. }\end{array}$ & Latente & $\begin{array}{l}\text { Actitudes, representaciones } \\
\text { ideológicas e imágenes } \\
\text { (con mayor o menor } \\
\text { evocación afectiva: } \\
\text { deseos). }\end{array}$ \\
\hline Barrera de la censura y la represión & $\begin{array}{l}\text { Lo reprimido } \\
\text { e inaccesible: } \\
\text { representaciones cosa. }\end{array}$ & Profundo & $\begin{array}{l}\text { Deseos, pulsiones, } \\
\text { tendencias profundas. } \\
\text { Imágenes simbólicas: } \\
\text { proyecciones } \\
\text { inconscientes. }\end{array}$ \\
\hline \multicolumn{2}{|l}{}
\end{tabular}

Fuente: Elaboración propia.

Si caracterizamos el nivel latente-preconsciente, centro de interés específico del presente trabajo y en no pocas ocasiones definido como el nivel propiamente sociológico del análisis del discurso (Colectivo IOÉ, 2010), es necesario diferenciarlo del llamado discurso implícito, con el que muchas veces se le equipara, a nuestro juicio, erróneamente. En un intento reciente de definición y acotación del discurso implícito, se ha elaborado una tipología de cuatro dimensiones del mismo (Ruiz, 2014). No obstante, a lo que el autor llama dimensiones 'no intencionales' del discurso implícito: discurso 'fallido' y 'subyacente', aquí proponemos situarlas más bien en el nivel latente del discurso, diferenciándolo de lo implícito, si entendemos por nuestra parte que este nivel se expresaría cuando hay consciencia del deseo o intención, que se hace evidente para el receptor. En lo implícito habría, necesariamente, voluntariedad (deseo, intención) consciente por parte de quién enuncia el discurso, de insinuar u ocultar aquello que se quiere expresar. Así interpretamos 
Maingueneau (1980: 152) cuando señala la doble utilidad de lo implícito, posibilitando decir algo sin ser considerado responsable de haberlo dicho, así como sustraer las posibles objeciones a lo dicho. Lo 'implícito no intencional', en la medida en que sería involuntario, se desarrollaría más bien fuera de la consciencia, de aquí la conveniencia de situarlo en lo latente, o si fuera el caso, en lo profundo. ${ }^{18} \mathrm{El}$ acto fallido es un ejemplo excelente de ello tal y como ha sido planteado por el psicoanálisis: no es que se produzca sin intención o deseo, sino que es la expresión no consciente de éste lo que lo produce, por tanto, el enfrentamiento o interferencia entre dos deseos. También la sociología ha situado el acto fallido en la expresión de una intención en un marco social inadecuado para la misma, de acuerdo a las normas sociales de dicho marco (Lahire, 1998: 145). Lo subyacente, en la medida en que trata de actos discursivos más bien irreflexivos, no reconocidos, automatizados, cuenta con deseos, intenciones, posiciones afectivas o elementos sociales (conflictos, intereses, hábitos...) no inmediatamente conscientes que dinamizan el discurso y en el que toman expresión, aunque sea veladamente. Las estructuras simbólicas e ideológicas de las imágenes preconscientes del consumo son un buen ejemplo de ello. Lo implícito, además, debe hacerse evidente por el receptor sin un esfuerzo excesivo, lo que no ocurre con el nivel latente, sobre el que muchas veces pasa inadvertido para el receptor, y ya hemos dicho que requiere, por lo menos, un mínimo trabajo de análisis para el investigador. La atención a ambos niveles de análisis probablemente sea necesaria, en función de la finalidad de la investigación.

Desde una óptica psicoanalítica, el nivel latente del discurso como expresión de lo preconsciente, supondría la expresión de un conocimiento que el sujeto de la enunciación no sabe que sabe. Eso es, lo que reinterpretando a Bollas (1991) desde el preconsciente llamaríamos 'lo sabido pero no pensado', aunque efectivamente, en nuestro caso y dadas ciertas condiciones se puede llegar a ser consciente de ello (con más o menos resistencias). Incluso podríamos hablar de modos más reflexivos y menos alejados de la consciencia que otros en el funcionamiento preconsciente. Por ejemplo, se habla de un preconsciente más automatizado en las imágenes y actitudes de consumo, y de uno más reflexivo en la manifestación de ideologías de clase, más elaboradas y racionalizadas (Arribas et al., 2013: 221).

${ }^{18}$ Podemos señalar que implícito y preconsciente-latente hacen referencia a niveles algo distintos de la realidad. Lo implícito es una característica del discurso, lo preconsciente-latente establece relación entre el discurso y quien lo enuncia; por tanto, es también relativo al actor social. Por otra parte, si lo 'implícito no intencional' solo lo es considerando la consciencia del hablante, podría corresponderse con el nivel latente. Preferimos, no obstante, la noción de preconscientelatente a la hora de referirnos a aquellos fenómenos discursivos sobre los que se puede inferir un deseo, intención o elemento genético de los mismos, no manifiestamente proferido en el discurso. Pues el nivel preconsciente, como hemos visto, recoge justamente esta característica. Si la comunicación implica una dimensión intencional y lo comunicado no siempre coincide o se agota en lo dicho manifiestamente, debemos aceptar una dimensión no consciente en la comunicación, que incluya deseos o intenciones no conscientes, más que una dimensión propiamente 'no intencional'. 
En el análisis de lo preconsciente, el nivel latente incorpora y pide atender para su aprehensión, a las dimensiones de lo que la pragmática lingüística denomina implicaturas, entendidas como significados adicionales de lo comunicado pero no dicho explícitamente (Grice, 1975); a la connotación de los mensajes y su código (Alonso y Fernández Rodríguez, 2006), así como a las hermenéuticas sociales (Giraud, 1972: 85) ${ }^{19}$ a la polisemia restringida, según la cual una expresión manifiesta o un significante pueden tener varios y distintos sentidos en función del uso que sujetos y grupos desarrollan del mismo (Ricoeur, 1975: 105); a las cadenas asociativas, reveladoras de los campos de valores significativos y afectivos de un hilo discursivo (Conde, 2009: 236; Jäger, 2003: 81); a los instrumentos retóricos o marcadores lingüísticos diversos (Meyer, 2003: 51-56); o a las estructuras sutiles de los textos (actos fallidos, entonaciones, estilos discursivos, estructura proposicionales), en cuanto que expresan las propiedades pragmáticas de la comunicación como el deseo, intención, posiciones emocional del hablante, etc. (Van Dijk, 2003b: 158).

El uso en el discurso de las mencionadas dimensiones implicaría un modelo preconsciente de conocimientos, valoraciones y deseos que se dan por supuesto, que pasan por alto en la práctica discursiva, en la medida en que se trata de contenidos adquiridos socialmente y compartidos colectivamente. Así es como pueden entenderse las inferencias elaboradas de Brown y Yule (1993: 320 y ss.), como complementos informativos socialmente compartidos de la comunicación. Los grupos sociales dan por sentado ciertos contenidos en la interacción y el discurso cotidiano, y los desarrollan intersubjetivamente como 'fundamento común'. Aunque desde otro marco teórico, pero coincidente con lo que aquí llamamos preconsciente, autores como Van Dijk (2003a) han situado estos contenidos en la llamada 'memoria de largo plazo', siendo ésta donde generalmente se encuentran las ideologías. Así, el sentido latente de un discurso ideológico, en tanto derivado del preconsciente de los sujetos, apuntaría hacia la dimensión intersubjetiva y comunicativa del discurso, y por lo tanto, en el nivel propiamente social y colectivo. Los discursos contienen y reproducen parte de dicha intersubjetividad de forma poco evidente, siendo por tanto su análisis aquello que nos proporciona conocimiento sobre la vida social, espacio de producción y desarrollo de las relaciones y sentidos intersubjetivos (Ruiz, 2009).

A modo de indicaciones generales, podemos decir que el análisis de lo latente, como el de lo manifiesto, tiende a culminar en un nuevo discurso -el del investigador y el informe. El punto de partida, tomando el método analítico de Freud, podría ser el sin sentido o, en todo caso, el análisis del contenido manifiesto, teniendo como objetivo metodológico hacer evidente el sentido latente, como decimos, ya presente en el discurso (Gutiérrez Brito, 2011: 115). Se trataría de hacerlo manifiesto, reconstruyéndolo, de acuerdo con los objetivos

${ }^{19}$ El análisis del código no se comprende en sentido estructuralista, sino como hacen los autores, situándolo en las lógicas sociales que lo producen. Se trataría de lo que Garfinkel llama 'indexicabilidad' para analizar el sentido de un discurso en un contexto dado (Íñiguez, 2003: 68), también cercano a lo llamado por Conde (2009: 167 y ss.) como 'configuración narrativa'. 
de la investigación, piedra angular del análisis sociológico del sistema de discursos (Conde, 2009). Ya que como observa Callejo (2001: 148), todos los discursos tienen más de un sentido, ${ }^{20}$ y son los objetivos de la investigación lo que va a orientar el análisis hacia el sentido latente concretamente buscado. Esto suele exigir un trabajo de análisis que contemple los distintos sentidos a los que se abren los textos, al mismo tiempo que un trabajo de dilucidación de cuáles son los sentidos más probables (Ricoeur, 1995: 90), capaces de dar cuenta del fenómeno social objeto de estudio.

La tarea de análisis, según de Lucas (1997), es fundamentalmente deductiva -o inferencial (Alonso, 1998: 210). ${ }^{21}$ Consiste en deducir de lo manifiesto el contenido latente y sacar conclusiones o hipótesis relativas a este nivel a través de la reconstrucción de los elementos latentes, poniéndolos en relación con la totalidad del corpus de textos de la investigación (Ricoeur, 1995; Conde, 2009). ${ }^{22}$ Es a partir de esta primera mirada 'integral' desde donde se suele prescribir una tarea de descomposición de los distintos componentes que forman los textos. Igual que hace Freud con los sueños, el mismo de Lucas $(1998: 139,140)$ indica que la descomposición tiene como finalidad el establecimiento de asociaciones, del tipo que sean, entre los distintos segmentos del texto. Primero habla de una descomposición sintagmática y, en segundo lugar, el añadido de las relaciones paradigmáticas correspondientes a cada una de ellas. La tarea de segmentación puede realizarse desde unidades complejas de sintagmas o microtextos, hasta unidades más simples. ${ }^{23}$ En estas unidades debe buscarse lo implicado y subyacente, a partir de aquellas dimensiones con las que anteriormente hemos caracterizado lo preconsciente. Las diferenciaciones y las relaciones que mantienen estos segmentos analizados, deben ir proporcionándonos elementos para la unificación o reconstrucción de lo latente. Construcción que, siguiendo nuevamente a Freud, responde a la tarea del investigador de destacar y recomponer fragmentos y sentidos relevantes para el análisis, recubriéndolos y aplicándolos después a los modelos teóricos pertinentes (Ibáñez, 1979: 322).

20 El carácter prácticamente infinito de un análisis cualitativo, hace que los objetivos de la investigación adquieran una relevancia crucial, tanto como puntos de partida como horizontes del análisis.

21 Aquí la deducción se usa en el sentido de la lógica y no en el sentido del método hipotéticodeductivo, de ahí su proximidad con la inferencia, que implica deducción. Así, la actividad deductiva o inferencial del análisis se inscribe plenamente en la lógica abductiva (Alonso, 1998: 210).

${ }^{22}$ Algunas perspectivas de análisis priorizan la tarea de descomposición analítica de los textos (véase Miles y Huberman, 1994).

${ }^{23}$ El uso de las nociones de microtextos y unidades sintagmáticas proviene de un esquema didáctico elaborado en 1999 por Alfonso Ortí. Aunque el autor no lo explicite, podemos pensar que con unidad sintagmática se refiere aquí, siguiendo la linguiística estructural, a la unidad de sentido, en cuanto que extensión lineal del lenguaje. El paradigma, marcaría la selección y combinación posible. En cuanto a la caracterización del microtexto, hacemos una analogía con los niveles de estructuración del texto de Van Dijk (1980). Así, el nivel microestructrual del texto se correspondería con el microtextual al que alude Ortí, referido a la estructura de las proposiciones y las relaciones entre ellas dentro de los textos que forman el corpus. En todo caso, estas nociones no se entienden aquí en su articulación en un discurso como estructuras previas a lo social, sino como determinadas por su uso o por hermenéuticas sociales y personales. 
La reconstrucción de lo latente implica analizar en estas unidades segmentadas o microtextos, lo que se dice y lo que no se dice manifiestamente en el discurso, lo que se contradice con éste, y lo que se articula con lo que podría haber dicho (Ibáñez, 1985b: 128), además de con lo que dicen los otros discursos. Esta tarea posibilitaría, más allá de realizar un análisis 'temático' (manifiesto) de aquello que abordan los sujetos, ahondar en lo connotativo, lo relacional, el contraste, lo conflictivo, dando con los esquemas de percepción y representación de los sujetos. Por ejemplo, una visión relacional del uso de ciertas expresiones puestas en contexto con la totalidad de los textos de la investigación (e incluso con lo ausente), permitiría determinar los sentidos preconscientes, distintos y concretos que tienen dichas expresiones, a veces realizadas con idénticos significantes, para determinados grupos sociales. Sería relevante aquí el análisis de determinadas 'palabras valija', en la medida en que posibilitarían dicha variabilidad significativa por su potencial polisémico (Deleuze, 1967: 73-79). También el análisis del sentido de la asociación discursiva entre determinados valores y prácticas, podría ser revelador de determinados esquemas preconscientes simbólicos e ideológicos de los sujetos investigados.

En cuanto a las posibles incoherencias (sociolingüísticas) del sentido latente, pueden entenderse, como sugiere Callejo (2002), como contradicciones en el campo social proyectadas en el discurso. Martín Criado (2014) ha subrayado la existencia de incoherencias en el discurso, consecuencia de la contraposición entres esquemas simbólicos e ideológicos en los mismos sujetos. Ya hemos señalado la importancia de su análisis para la reconstrucción de lo latente, en la medida en que estos esquemas responden a articulaciones preconscientes relativas a situaciones o contextos sociales diversos. Si definimos el preconsciente por su carácter social y colectivo, podemos aceptar la posibilidad de la existencia de contradicciones entre contenidos preconscientes, ${ }^{24}$ especialmente el de aquellos configurados en la llamada socialización secundaria (Lahire, 1998), así como de aquellas formaciones ideológicas articuladas en el preconsciente, que reproducen las contradicciones con las que se encuentra el sujeto en el campo social. De este modo, toman expresión los antagonismos sociales y las posiciones ideológicas diferenciales en los sujetos y entre estos (Laclau y Mouffe, 1985; Giddens, 1984: 222 y ss.). En cuanto a la interpretación de las contradicciones entre niveles de sentido -manifiesto y latente-, en tanto que conflictos intra e intersubjetivos expresados en el discurso, no son problemáticas desde el psicoanálisis dado que los niveles superficiales de consciencia tenderían a encubrir lo latente y profundo, a veces presentándolo de forma invertida. ${ }^{25}$ Con la contradicción en y entre niveles de sentido, se

${ }^{24}$ Freud habla de una 'segunda censura' en el paso del preconsciente al consciente, no tanto marcada por la deformación como por la selección de los contenidos. Esto abre la puerta a considerar la selección de contenidos que no son perturbadores o dañinos para el individuo (no censurables), pero sí que impliquen incoherencias o contradicciones desde una óptica social.

${ }_{25}$ Así lo hemos observado, por ejemplo, en la presentación metodológica del análisis sociológico de los vínculos humanos mediante la narración de chistes (véase Izquierdo y Barbeta, 2014). Por otra parte, Conde (2009: 237) propone el análisis en clave sociológica de los desplazamientos 
establece, sin duda, un elemento relevante para el análisis.

Finalmente, el análisis sociológico del nivel latente del discurso requeriría también de un momento de interpretación. Lo latente no solo es aquello preconsciente implicado en lo dicho y que puede ser deducido, sino que puede incluir también la interpretación motivacional del deseo o intención que fundamenta lo comunicado (Wilden, 1979: 308), y que en definitiva revela su sentido (Brabant, 1976: 15). Pero además, en la medida en que se trata de una interpretación sociológica, lo latente como expresión del preconsciente colectivo, tiene que ser considerado no en un marco puramente textual, sino puesto en relación con el contexto y los lugares sociales desde donde es producido el discurso ideológico (Alonso, 1998 y 2013; Van Dijk, 2012). Si por autores como Bronckart (1985) sabemos de la relación de los parámetros contextuales con la determinación del discurso y el significado del mismo, podemos afirmar con Ortí (1986: 166) que 'la función del sociólogo se reduce a relacionar la orientación ideológica de los discursos con la génesis y reproducción de los procesos sociales. O lo que es lo mismo, el contexto de su interpretación está representado por una visión global de la situación y del proceso histórico en que emergen los discursos ideológicos'. Serán necesarias, por tanto, la interpretación de las relaciones entre los sentidos latentes de los discursos y los procesos sociales que contribuyen a generarlos.

Dentro de la corriente de análisis de la escuela del cualitativismo crítico madrileño, se establecen procedimientos y niveles de análisis del discurso que pueden leerse y realizarse -como de hecho explicitan los autores- desde lo latente de los discursos (Conde, 2009; Callejo, 2001; Alonso, 1998). También desde el Análisis Crítico del Discurso plantean distintas propuestas de análisis referidas, en buena parte de los casos, al mismo nivel latente (Wodak y Meyer, 2003; Van Dijk, 2000).

Desde una enfoque artesanal y globalizador en el planteamiento de la metodología cualitativa (de Lucas y Ortí, 1995), parece difícil ofrecer un catálogo cerrado de procedimientos bien formalizados para su aplicación automática al análisis de lo latente; más aún si entendemos que se trata de un nivel transversal en el análisis del discurso. Esto es, una orientación aplicada a la globalidad de los textos de una investigación y a buena parte de los procedimientos concretos, abiertos y flexibles que las tradiciones de análisis anteriormente citadas utilizan. No obstante, nos proponemos señalar, de forma esquemática, algunas indicaciones generales sobre el abordaje del nivel latente del discurso, como vía posible de acercamiento al preconsciente colectivo. Seguimos algunos de los elementos ya señalados.

freudianos, como indicadores de conflicto en el discurso. 
- Determinar los objetivos de la investigación para 'filtrar' aquello que interesa del discurso y acercarse así al sentido buscado.

- Situarse en una perspectiva de la reconstrucción del sentido latente: es una elaboración del investigador.

- Lectura y consideración global y continua del corpus de textos (mirada integral): elaboración de las primeras conjeturas como momento intuitivo.

- Tarea de descomposición del contenido manifiesto: segmentación por el investigador de microtextos o unidades sintagmáticas, entendidas aquí desde su uso social.

- Cortes entre unidades diferenciales en el contenido manifiesto: finalización elementos relevantes, introducción nuevos temas o elementos, cambios de temática o intervención moderador/ entrevistador.

- Diferenciación microtextos i sintagmas más simples.

- Relaciones entre elementos microtextuales, o entre los paradigmas y los sintagmas simples: establecimiento de asociaciones mediante inferencia de lo dicho (manifiesto) con lo ausente pero implicado: inadvertido, no reconocido, condensado, contradictorio, etc...

- Establecimiento de modelos arquetípicos, polarizaciones y agrupaciones del sentido de los textos de la investigación a partir de lo implicado. Aplicar estas articulaciones a los procedimientos más o menos formalizados que aparecen en la literatura citada: posiciones discurso, espacios semánticos, hilos discursivos, códigos, marcadores lingüísticos, etc., con los objetivos de la investigación como horizonte.

- Atender a actos fallidos, a elementos no verbales de las dinámicas.

- Modelo de contextualización interpretativa: establecer conexiones entre los puntos anteriores y los condicionantes extralingüísticos: contexto histórico, conflictos sociales e ideológicos, deseos, intereses no manifiestos.

- Revisión conjeturas explicativas e interpretativas del sentido latente del discurso. 
Figura 1. Secuencia esquemática del análisis del nivel latente del discurso

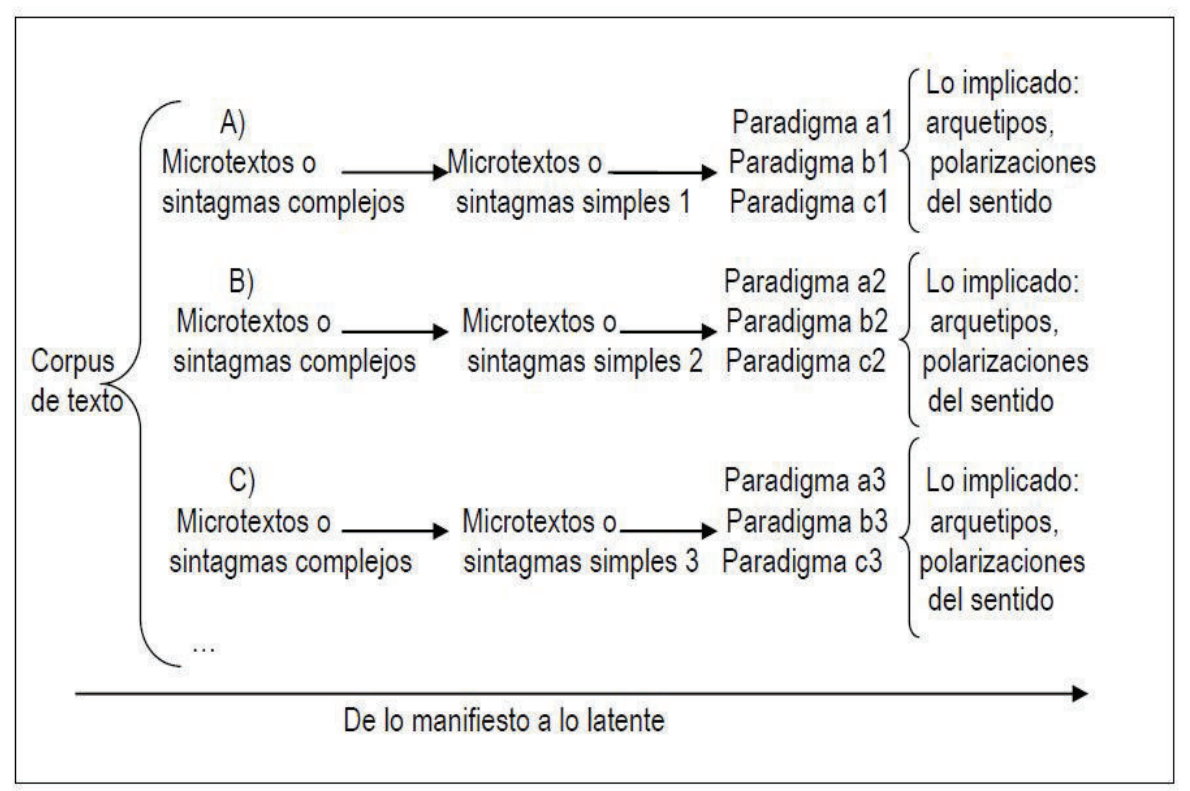

\subsection{Ejemplos de análisis}

A continuación se aportan a modo de ejemplo los análisis realizados en dos investigaciones empíricas en las que se analiza el nivel latente de los discursos. Al tratarse de investigaciones con sus objetivos concretos, lo ejemplificado no debe tomarse como el único análisis posible, sino como uno de los sentidos latentes que contribuyen a cubrir los objetivos y preguntas de investigación.

Una de las investigaciones paradigma del análisis del preconsciente colectivo, podría ser el estudio sobre las actitudes ante el aborto desarrollado por de Lucas y Ortí (1983). Este trabajo se elabora en el contexto del debate sobre el Proyecto de Ley de despenalización del aborto en el Estado español. Sus objetivos eran determinar las posiciones ideológicas existentes en torno a los distintos supuestos de despenalización del aborto previstos en dicho Proyecto, así como conocer el sistema de representaciones sociales sobre la cuestión general del aborto. ${ }^{26}$ El contexto social e ideológico de la investigación se encuentra marcado por el desarrollo de la transición postfranquista, en el que se van ensanchando los bloques ideológicos conservador y liberal, frente a las minorías patriarcales y feministas, en asuntos como la situación de la mujer y la

${ }^{26}$ Puede encontrarse un resumen de la investigación, no publicada hasta el momento, en Ramos (1983).

EMPIRIA. Revista de Metodología de Ciencias Sociales. N. 31, mayo-agosto, 2015, pp. 97-129. ISSN: 1139-5737, DOI/empiria.31.2015.14539 
familia.

Atendemos a un aspecto muy concreto de dicho análisis: el sintagma /en conciencia/, destacado en algunos fragmentos del informe. En el transcurso de la investigación los autores observan la importancia que tiene el uso que los grupos hacen de dicha expresión, como fundamento ideológico de las distintas posiciones discursivas existentes ante la cuestión del aborto. El análisis señala tres sentidos latentes asociados al uso de /en conciencia/:

A) El correspondiente al discurso integrista, que niega la legitimidad moral del citado sintagma en la forma como es usado por los núcleos no integristas; aquí /en conciencia/ toma el sentido de no tener conciencia, dado que ésta solo representa la expresión de una Ley absoluta y natural, que se justifica en términos religiosos o metafísicos. Tiende a constituirse en segunda persona como discurso del /tú/ o de subordinación prohibicionista.

B) El correspondiente a una fórmula de compromiso propia del discurso tolerante, por la que /en conciencia/ adquiere un sentido ambiguo que connota todo estado de indecisión, propio de la conciencia individual. Así, el uso que se da a /conciencia/ se asocia al sentido de una 'libertad individual', aunque condicionada por la ley, la moral que el sujeto puede transgredir o no: sentido que entraña el correlato afectivo latente de la culpa. Este sentido desplaza la /conciencia/ de su sujeción a la Ley (absoluta) hacia la conciencia en situación, dependiente de una realidad situacional, secularizada e individual. Este desplazamiento es analizado por primera vez por los autores en el grupo de discusión del que extraemos el siguiente fragmento textual, donde se muestra esta desvinculación preconsciente de /la conciencia/ respecto la Ley, para asociarla a las costumbres, a las instituciones y, además, a las situaciones concretas que viven los individuos. Tiende a constituirse en tercera persona como discurso sobre /el/ en cuanto conciencia en situación. Con el análisis de los otros grupos (análisis integral), se observa que el fundamento ideológico de /en conciencia/ es, para la posición discursiva tolerante, la aceptación del pluralismo que en el contexto de la investigación se asocia a la secularización de la cuestión del aborto.

C) El correspondiente al discurso progresista, en el que la /conciencia/ adquiere el sentido de decisión racional, autónoma, fundada en el derecho personal. Tiende a constituirse en primera persona como discurso del / yo/ o autoafirmación progresista.

A partir del siguiente fragmento señalamos algunos de los elementos para el análisis de los sentidos latentes de /en conciencia/ esbozados. 
- 'Yo te digo que yo, pues en conciencia, es el mismo problema, es o sea, el mismo hecho en, teniéndolo aqui o sea abortando aquí que irse a abortar a... (3)

-Sí, aquí te meten en la cárcel. ;Hombre! (6)

-Bueno, pero si ese no es el problema. (3)

-...eso, que la conciencia de cada una y ya está. Las que tienen problema o no. Yo ahora mismo, si tuviera que firmar en contra del aborto, en contra del aborto. Porque es que ahora mismo no estoy mentalizada para eso. (4).

-Yo tampoco. En ningún caso. (3)

-Yo, en una violación de una niña, sí, por supuesto. (6)

-Yo no. (3) O sea que...

(6)

-Pero siempre que se haga un reconocimiento en las veinticuatro horas primeras.

-Como lo legalicen, di tú que vas a ver más de un... (3) (...)

- El aborto lo ha habido de toda la vida, porque en la época del franquismo había muchísimos abortos y no se enteraba nadie, y lo había. (6)

-Pero en su conciencia. (3)

-Bueno, pues muy bien con la conciencia, pero que ha existido. La conciencia está en... (6)

-Que iba a haber... (2)

-Que habría muchísimos, pero si es que los hay a punta pala. (6)

-Ahora hay abortos así. (1)

-Pero si es que los hay. (6)

-No, ¿por qué iba a haber más abortos? Habría... (4)

-Pues a lo mejor no. (6) (...)

-Pues yo no. ¿Qué consecuencias podría traer? Es lo mismo que el otro día cuando el debate de la droga. Eso quien quiera lo hará y quien no quiera no lo hará. (4) (...)

-Eso ya va en conciencia de cada cual. Y yo creo que con una buena formación, desde un principio, no pasa nada, no pasa nada. Y como no ha pasado. Y habrá quien vaya al extranjero todavía y habrá quien lo haga aquí y habrá quien no lo haga. (4)

-Pero realmente el hecho es el mismo que va aquí o que vaya... (3)

-Yo creo que legalizando el aborto, legalizando la droga, todas esas cosas, es que se va deformando la conciencia de las personas y la moral de un país, de tal forma que yo no sé donde vamos a llegar'. (2)

(GD, madres de familia no numerosa, 30-40 años, amas de casa inactivas, estatus medio-alto, Mérida, febrero 1983).

Siguiendo el análisis del conjunto del grupo, en este tramo de la discusión están ya más o menos diferenciados los núcleos y fracciones discursivas. ${ }^{27}$

Para una fracción la legalización del aborto no es problemática, porqué siempre los ha habido. Sitúan el problema fuera de la moral, de la conciencia,

${ }^{27}$ Se ha seguido la transcripción policopiada del grupo de discusión, localizada en el antiguo despacho del curso de Praxis de la sociología del consumo, en la UCM. Agradezco a Araceli Serrano y a Matilde Fernández-Cid el acceso al mismo.

EMPIRIA. Revista de Metodología de Ciencias Sociales. N. ${ }^{\circ}$ 31, mayo-agosto, 2015, pp. 97-129. ISSN: 1139-5737, DOI/empiria.31.2015.14539 
definiéndolo como realidad. La conciencia se asocia a la ley moral interiorizada

Para otra, /en conciencia/ tiene un el valor ambiguo, establecido por el sentido de libertad de elección individual, y por el sentido de conciencia como ley moral interiorizada. La libertad de transgredir o no la ley moral (valores y normas socio-culturales) tiene, como hemos dicho, su correlato culpable. Lo relevante es que desde el sentido de la elección individual, el marco de la ley moral en sí mismo queda latentemente transformado: cuando la conciencia es referida a la libertad de elección, el marco de la moralidad -de la concienciatiende a ser la misma conciencia situacional del individuo (sentido B).

Vuelve a aparecer en el extracto de texto la conciencia como límite, como moral en proceso de degeneración. Sin embargo, en el contexto de la frase y del grupo, como señalan de Lucas y Ortí (1983: 148), aquí la conciencia no procede de la Ley como mandato absoluto, abstracto y universal, sino que se configura desde 'las costumbres e instituciones públicas seculares'. Lo que supone un primer reconocimiento preconsciente de la /conciencia/ del individuo como ámbito autónomo y relativo, frente la Ley absoluta de base religiosa (sentido B).

El segundo ejemplo es el de una investigación más reciente, parcialmente expuesta en Barbeta (2015), dirigida a investigar el fenómeno del consumo ecológico. Uno de sus objetivos principales era desentrañar la imagen del consumo ecológico y sus procesos motivacionales básicos. Aquí el contexto social se encuentra marcado por la crisis financiera y por los debates acerca de los límites de la sociedad de consumo, presentes en algunos grupos sociales.

Nos referimos a un momento concreto del análisis, relativo a un conflicto que vivían los propios consumidores ecológicos, y que de hecho, expresaba la actitud de los mismos ante el consumo como lógica motivacional. Dicho conflicto, ${ }^{28}$ de carácter preconsciente, se producía por la tensión entre dos deseos con sentidos enfrentados: uno de los cuales podríamos llamar 'consumista', y el otro 'restrictivo' o 'prohibitivo'. En el marco de la investigación, la resolución de dicha dinámica motivacional conflictiva a favor del segundo tipo de deseo, revestido con valores ideológicos socio-ambientalistas, expresaba una orientación con un sentido específico hacia el consumo ecológico: asociado a la defensa social y ambiental, a una actitud ascética, etc.

${ }^{28}$ Los conflictos en los que se oponen exigencias internas contrarias, pueden implicar distintos niveles de consciencia. Aquí nos centramos en el preconsciente. No obstante, esto no significa que el mismo conflicto pueda tener su correlato inconsciente y profundo. 
E: Y qué sería un uso racional...

D: Pues no tener un IPhone 4 cuando toca tal vez...

D: Yo creo que no puede haber uso racional. Si quisieras ser, osea... yo, yo tengo un móvil, yo tengo un ordenador, lo que pasa es que por ejemplo, el ordenador, no tenemos uno para cada persona en mi casa, no, osea que los compartimos. Esto está... mínimamente bien, no, pero yo creo que realmente, no deberíamos tener. Pero bueno ...”.

D: "Yo creo que lo que está bien es que hacemos consumo crítico, no, antes de todo. Al final acabaremos yendo al Zara o no, pero sabemos lo que hay, no, que eso es lo importante. Y eso, no, que tú vas a la cooperativa y, y consumes próximo, ecológico, tal claro... Pues podríamos sudar e ir cada, una vez a la semana consumo, llenar el congelador y comer judías trituradas y cebollas congeladas. Pero no lo elegimos. Quiero decir, dentro de lo que quizá sería lo más práctico, y económicamente más ... a todo el mundo le saldría fantástico, pues sería aquello, pero dices, dentro de eso, yo prefiero construir una alternativa y claro, de aquí y que entonces, como estoy en esta alternativa pues ya me vuelvo (...) radical e integrista ecológico ... es que al final es eso, es que te acabas volviendo... quiero decir que si no acabas loco, quiero decir...

H: ...claro te estresas..

D: ...no lo puedes conseguir, te estresas mucho...Cada día mil cosas...”.

(00:12:30-1, GD1, mixto, jóvenes-adultos independientes, clases medias con estudios superiores, Barcelona, 2011).

Elementos para el análisis del nivel latente en el que se expresa este conflicto.

- Imposibilidad práctica de llegar al /uso racional/ de los objetos de consumo, entendido -contradictoriamente- como ideal o expectativa. Concepción de /uso racional/ inscrita en un código socio-ambientalista, y asociada significativamente a una actitud ascética, de bajo consumo, a valores de defensa ambiental, etc. Los consumidores tienden a ponerla en relación semántica con lo /ecológico/ y /el consumo crítico/. Tal imposibilidad marca de forma latente el núcleo del conflicto.

- Deseo con sentido 'consumista': expresado por lo que se tiene (objetos de consumo) y lo que se podría hacer en cuanto a las prácticas de consumo, de seguir semejante deseo (como posibilidad efectiva); se asocia a valores significados positivamente: lo práctico, lo económico, lo fantástico. También se insinúa un cierto imperativo consumista ('cuando toca, a lo mejor...'), coherente con la concepción de imposibilidad. Tiende a expresarse en primera persona del singular, desde el yo.

- Deseo con sentido 'restrictivo o prohibicionista': expresado por la prohibición de lo que se hace en la práctica del consumo y de lo que se puede llegar a hacer en el consumo (como posibilidad negada); en todo caso, restricción o prohibición del deseo anterior, que se reconoce realizar en mayor o menor medida. Tiende a expresarse desde el / nosotros/ en sentido colectivo, que revela un sentido latente grupal. 
También -en este y otros fragmentos de texto- desde la segunda persona del singular, como objetivación que los consumidores hacen de ellos mismos.

- Identificación con el deseo con sentido 'restrictivo o prohibicionista', y justificación y racionalización del mismo con los valores ideológicos socio-ambientalistas, asociados en este caso al consumo ecológico en cooperativas. La realización de este deseo entraña el correlato del conflicto anterior en un plano afectivo: deseo de aprobación y reconocimiento por una parte, y la expresión de un cierto malestar asociado a las dificultades y la 'dureza' de la actitud restrictiva o prohibicionista. Esta disparidad afectiva preconsciente no deja de revelar, no obstante, la presencia contradictoria de la 'doble presión' del deseo con sentido 'consumista' y del deseo con sentido restrictivo: del mismo conflicto aparece la necesidad de reconocimiento positivo, derivada de la negación (restricción, prohibición) de aquello que como posibilidad efectiva se podría hacer en las prácticas de consumo, y no se hace en tal medida.

\section{CONCLUSIONES}

Como han puesto de manifiesto un número importante de sociólogos, la obra de Freud en general y algunos de sus aspectos en particular, ha resultado altamente productiva para el interés y el desarrollo de la sociología. Aquí nos hemos limitado a abordar un aspecto muy concreto de su teoría, como es la noción de preconsciente y su relación con el lenguaje, desde una lectura metodológica orientada al análisis sociológico. Siguiendo lo que Ángel de Lucas y Alfonso Ortí, entre otros sociólogos, pusieron de manifiesto, hemos desarrollado la noción freudiana del preconsciente como sistema del aparato psíquico que se constituye como sede principal de los procesos de incorporación y socialización que viven los individuos. Sistema en el que además, se inscribe la dimensión psíquica y social de la adquisición del lenguaje.

El abordaje realizado sobre el preconsciente nos aporta elementos que nos aproximan a una explicación teórica sobre cómo los individuos, en su desarrollo, van adquiriendo la capacidad de diferir las descargas energéticas provenientes de la movilización pulsional inconsciente, a través del lenguaje. Esta concepción puede ser especialmente relevante para la sociología, en la medida en que las formas en que el lenguaje se estructura o canaliza en el preconsciente vienen directamente mediadas por la praxis social, es decir, por las formas en que los grupos sociales lo incorporan y van determinando su uso desde marcos colectivos. Así, el preconsciente puede ser comprendido como una suerte de 'almacén' dinámico y activo. Por una parte actuaría como filtro para el que deben pasar, transformados, los contenidos inconscientes. Por otra -aunque conectada con la anterior-, un filtro que actualiza determinadas formas de respuesta (en forma de esquemas, discursos o comportamientos), 
en función de la situación y contexto presentes, y de los discursos sociales circulantes. Las capacidades asociativas que pone en juego el preconsciente establecerían las relaciones entre lo interior y lo exterior de los sujetos. Debemos reconocer, no obstante, la dimensión estructurante -en términos de Bourdieu- del preconsciente, su papel en los procesos de nominación -en términos de Ricoeur-, como campo a explorar más profundamente. Lo mismo podemos decir sobre la utilización teórica del preconsciente para atender a los procesos reflexivos y estratégicos que sin duda juegan un papel importante en los procesos de resignificación discursiva.

Esta perspectiva, como hemos ido viendo, sí ha permitido acercarnos al modo en que se reproducen las formaciones ideológicas, y concretamente, la eficacia de la interpelación de los discursos ideológicos. Partiendo de que las ideologías tienden a expresarse en los usos del lenguaje por parte de sujetos y grupos, la conformación de los sujetos ideológicos podrá definirse -por lo menos, en parte- a partir de la capacidad de los discursos ideológicos de cuajar en el sistema preconsciente de los mismos, y de la capacidad de este sistema de mediar en el devenir consciente de las pulsiones movilizadas por los discursos. Lo ya incorporado en el preconsciente y la capacidad de asociación y evocación con el contexto socio-histórico presente, han sido definidos como fundamentales para el éxito (siempre relativo) de la interpelación ideológica.

Con una lectura metodológica de estas concepciones, se han establecido algunas implicaciones clave para el análisis del discurso ideológico, tarea central de la sociología cualitativa. En primer lugar, la génesis social del preconsciente plantea un nivel de análisis relevante para la sociología en la medida en que fundamenta una mirada específicamente sociológica del análisis del discurso. En segundo lugar, junto con los otros niveles de consciencia que recoge la primera tópica de Freud, nos permite establecer unas correspondencias entre éstas y los niveles de análisis y sentido que deben trabajarse, detectarse e interpretar, para dar cuenta de la dimensión preconsciente del discurso. El sentido latente correspondiente al preconsciente tiene la virtud de proporcionar, como decimos, los elementos propiamente sociales y colectivos de los discursos, sujetos a condicionantes extralingüísticos como son la relaciones sociales, sus correlatos afectivos, etc. Posibilita, así mismo, establecer determinadas categorías analíticas (actitudes, representaciones...) útiles para el trabajo de análisis del discurso.

En cuanto a la tarea de análisis del nivel latente, hemos visto que no existen procedimientos excesivamente formalizados, pues según Ibáñez (1979: 320) no son posibles muchas reglas a priori que determinen cómo proceder en el análisis del sentido latente del discurso. No obstante, como apuntes generales, hemos señalado que consiste en un trabajo deductivo o inferencial e interpretativo, que parte del análisis de lo manifiesto de los discursos, teniendo como fin la reconstrucción y revelación de un sentido latente concreto, no evidente y en parte determinado por los objetivos de la investigación. La consideración de los elementos pragmáticos de la comunicación, de las dimensiones metalingüística, connotativa, polisémica y dialógica del lenguaje, así como de los aspectos contradictorios, incoherentes y afectivos, son fundamentales en el ejercicio 
de descomposición y re-contextualización en la totalidad del corpus, de los elementos latentes. Estas dimensiones se condensan en lo implicado del discurso manifiesto, que es aquel que puede segmentarse para analizar las articulaciones latentes que de alguna forma lo sustentan. El análisis de lo latente admite un carácter transversal en el conjunto del procedimiento de análisis, de tal forma que puede aplicarse al conjunto de procedimientos propuestos por las corrientes críticas del análisis del discurso anteriormente mencionadas. En cuanto a la lógica de la validación de las interpretaciones, en el análisis sociológico del discurso los sentidos latentes establecidos podrán validarse siguiendo la lógica de la probabilidad (Ricoeur, 1995: 90, 91), entendiendo ésta dentro de un marco abductivo (Alonso, 1998; Ruiz, 2009). Siempre y cuando la interpretación de los sentidos latentes, dentro de un marco científico intersubjetivo, nos permita dar cuenta de los fenómenos investigados y nos proporcionen unas cuotas de inteligibilidad suficientes sobre dichos fenómenos

\section{BIBLIOGRAFÍA}

ANZIEU, D. (1981) 'Para una psicolingüística psicoanalítica: breve balance y cuestiones preliminares', Anzieu, Didier, et.al., Psicoanálisis y lenguaje, del cuerpo a la palabra. Buenos Aires. Kapelusz.

ALONSO, L. E. (1998) La mirada cualitativa en sociología. Madrid, Fundamentos.

ALONSO, L. E. (2002) 'Los mercados lingüísticos o el muy particular análisis sociológico de los discursos de Pierre Bourdieu', Estudios de sociolingüística: Lenguas, sociedades e culturas, 3 (1): 111-132.

ALONSO, L. E. (2013) 'La sociohermenéutica como programa de investigación en sociología', Arbor: Ciencia, Pensamiento y Cultura, 189-761:1-15.

ALONSO, L. E. Y FERNÁNDEZ RODRÍGUEZ, C. (2006) 'Roland Barthes y el análisis del discurso', Empiria, Revista de metodología de ciencias sociales, 12:1236.

ALTHUSSER, L. (1965) 'Ideología y Aparatos ideológicos del estado', Zizek, S., (coord.) Ideología, un mapa de la cuestión. Buenos Aires, Fondo de Cultura Económica.

ARRIBAS, J. Ma . (coord.) (2013) Sociología del consumo e investigación de mercados. Una guía didáctica. Madrid, UNED.

BAJTIN, M. (1982) 'El problema de los géneros discursivos', Bajtin, M. Estética de la creación verbal. Madrid, Siglo XXI.

BARBETA VIÑAS, M. (2015) 'Entre renúncies, temors i deures: anàlisi de l'estructura motivacional del consum ecològic', Papers, Revista de Sociologia, 100 (1 ): 5-33.

BENVENISTE, E. (1971) Problemas de lingüística general. México, Siglo XXI.

BERGER, P. (1963) Invitació a la sociología. Barcelona, Herder.

BOLLAS, CH. (1991) La sombra del objeto. Psicoanálisis de lo sabido no pensado. Buenos Aires, Amorrortu.

BOURDIEU, P. (1985) ¿Qué significa hablar? Torrejón de Ardoz, Akal.

BRABANT, PH. (1976) Claves para el psicoanálisis. Barcelona, Los libros de la Frontera.

BRONCKART, J. P. (1985) Le fonctionnement des discours. Paris, Delachaux y Niestlé. BROWN, G Y YULE, G (1993) Análisis del discurso. Madrid, Visor. 
CALLEJO, J. (2001) El grupo de discusión: introducción a una práctica de investigación. Barcelona, Ariel.

CALLEJO, J. (2002) 'Grupo de discusión: la apertura incoherente', Estudios de sociolingüística: Lenguas, sociedades e culturas, 3 (1): 91-109.

CODERCH, J. (2006) 'Psicoanálisis y neurociencia', Revista de Psicoterapia, XVI (62): 35-52.

CODERCH, J. Y CODOSERO, A. (2013) 'Puntos de unión y diálogo entro lo explícito e implícito en el pensamiento psicoanalítico’, Temas de Psicoanálisis, 5: 1-36.

COLECTIVO IOÉ. (2010) ‘Para qué sirve el grupo de discusión? Una revisión crítica del uso de técnicas grupales en los estudios sobre migraciones', Empiria, Revista de metodología de ciencias sociales, 19: 73-99.

CONDE, F. (2009) Análisis sociológico del sistema de discursos. Madrid, Centro de Investigaciones Sociológicas.

DAMASIO, A. (1999) La senación de lo que ocurre: cuerpo y emoción en la construcción de la consciencia. Barcelona, Crítica, 2001.

DELEUZE, G. (1969) Lógica del sentido. Barcelona, Paidós, 2005.

DUCROT, O. (1986) El decir y lo dicho. Polifonía de la enunicación. Barcelona, Paidós.

EAGELTON, T. (1995) Ideología: una introducción. Barcelona, Paidós.

ERDELYI, M. H. (1987) La psicología cognitiva de Freud. Barcelona, Labor.

FAIRCLOUGH, N. (1995) Critical discourse analysis: the critical study of language. London, Longman.

FREUD, S. (1896) 'Cartas a Wilhelm Fliess (1887-1904)', Obras Completas Sigmund Freud. Buenos Aires, Amorrortu, 1986.

FREUD, S. (1900) 'La interpretación de los sueños', Obras Completas Sigmund Freud. Buenos Aires, Amorrortu, 1986.

FREUD, S. (1915) 'Metapsicología', Obras Completas Sigmund Freud. Buenos Aires, Amorrortu, 1986.

FREUD, S. (1923) 'El yo y el ello', Obras Completas Sigmund Freud. Buenos Aires, Amorrortu, 1986.

FURTH, H. G. (1990) El conocimiento como deseo. Un ensayo sobre Freud y Piaget. Madrid, Alianza Editorial, 1992.

GIDDENS, A. (1984) La constitución de la sociedad: bases para una teoría de la estructuración. Buenos Aires, Amorrortu, 1995.

GIDDENS, A. (1989) Sociología, Madrid, Alianza, 1994

GLYMOUR, C. (1991) 'Los androides de Freud', Neu, Jerome (comp.) Guía de Freud. Cambridge, University Press, 1996.

GRICE, H. P. (1975) 'Lógica y conversación', Valdés, L.M. (ed.) La búsqueda del significado. Madrid, Tecnos, 1991.

GUIRAUD, P. (1972) La semiología. México, Siglo XXI, 1985

GUTIÉRREZ BRITO, J. (2011) 'Grupo de discusión. ¿Prolongación, variación o ruptura con el focus grup?', Cinta de Moebio: Revista Electrónica de Epistemología de Ciencias Sociales, 41: 105-122.

HJELSMLEV, L. (1968) El lenguaje. Madrid. Credos, 1971.

IBÁÑEZ. J. (1979) Más allá de la sociología: el grupo de discusión: teoría y crítica. Madrid. Siglo XXI.

IBÁÑEZ, J. (1985a) 'Las medidas de la sociedad', Revista Española de Investigaciones Sociológicas, 29: 85-128.

IBÁÑNEZ, J. (1985b) ‘Análisis sociológico de textos y discursos', Revista Internacional de Sociología, 1: 119-162. 
ÍÑIGUEZ, L. (ed.) (2003) Análisis del discurso. Manual para las ciencias sociales. Barcelona, UOC.

IZQUIERDO, M. J. Y BARBETA VIÑAS, M. (2014) 'Notas metodológicas sobre el análisis de los vínculos grupales mediante la identificación de las asociaciones de sentido en los chistes', (en revisión).

JÄGER, S. (2003) 'Discurso y conocimiento: aspectos teóricosy metodológicos de la crítica del discurso y del análisis de dispositivos', Wodak, R. y Meyer, M., Métodos de análisis del discurso. Barcelona, Gedisa.

KANDEL, E. (1999) 'Biology and the future of psychoanalysis: a new intellectual framework for psychiatry revisited', American Journal of Psychiatry, 156: 505-524.

KRESS, G. Y HODGE, B. (1979) Language and ideology. London, Routledge.

LACLAU, E. Y MOUFFE, CH. (1985) Hegemonía y estrategia socialista. Madrid, Siglo XXI, 1987.

LAHIRE, B. (1998) El hombre plural. Barcelona, Edicions Bellaterra.

LAPLANCHE, J. Y PONTALIS, J.-B. (1967) Diccionario de psicoanálisis. Barcelona, Paidós, 1993.

LORENZER, A. (1970) Crítica del concepto psicoanalítico de símbolo. Buenos Aires, Amorrortu, 1976.

LORENZER, A. (1972) Bases para una teoría de la socialización. Buenos Aires, Amorrortu, 1978.

LUCAS DE, Á. (1990) "Fantasmática de la publicidad", Cuadernos Contrapunto: Publicidad: Semiótica e Ideología, pp.65-76, Madrid.

LUCAS DE, Á. (1997) 'Teorías de la ideología', transcripción de la sesión realizada el 24/2/1997 en el marco del curso de posgrado de Praxis de sociología del consumo e investigación de mercados, UCM.

LUCAS DE, Á. (1998) 'La primera tópica freudiana', Arribas, J.M. (coord.) Sociología del consumo e investigación de mercados. Una guía didáctica. Madrid, UNED, 2013.

LUCAS DE, Á. Y ORTÍ, A. (1983) Representaciones colectivas sobre la mujer y la familia (un análisis de las actitudes sociales ante el aborto mediante discusiones de grupo). Madrid, Estudio 1394, CIS. (informe no publicado).

LUCAS DE, Á. Y ORTÍ, A. (1995) 'Génesis y desarrollo de la práctica del grupo de discusión: fundamentación metodológica de la investigación social cualitativa', Investigación y Marketing, 47: 6-9.

MAINGUENEAU, D. (1980) Introducción a los métodos de análisis del discurso: problemas y perspectivas. Paris, Hachette.

MARTÍN CRIADO, E. (1998) 'Los decires y los haceres', Papers, Revista de Sociologia, 56: 57-71.

MARTÍN CRIADO, E. (2014) 'Mentiras, inconsistencias y ambivalencias. Teoría de la acción y análisis del discurso', Revista Internacional de Sociología, 72 (1): 115-138.

MEYER, M. (2003) 'Entre la teoría, el método y la política: la ubicación de los enfoques relacionados con el ACD', Wodak, R. y Meyer, M., Métodos de análisis del discurso. Barcelona, Gedisa.

MILES, M. B. Y HUBERMAN, A. M. (1994) Qualitative Data Analysis. An expanded Source Book. London, Sage.

ORTÍ, A. (1986) "La apertura del enfoque cualitativo o estructural: la entrevista abierta semidirectiva y la discusión de grupo", a García Fernando. M, Ibáñez. J, Alvira. F (comps.) El análisis de la realidad social. Métodos y técnicas de investigación. Madrid, Alianza editorial. 
ORTÍ, A. (1988) 'Para analizar el populismo: movimiento, ideología y discurso populistas. (El caso de Joaquín Costa: populismo agrario y populismo españolista imaginario)', Revista de Historia Social, 2: 75-98.

ORTÍ, A., (1993) 'El proceso de investigación de la conducta como proceso integral: complementariedad de las técnicas cuantitativas y de las prácticas cualitativas en el análisis de las drogodependencias', VVAA, Las drogodependencias: perspectivas sociológicas actuales. Madrid, Colegio Nacional de Doctores y Licenciados en Políticas y sociología.

ORTÍ, A., (1994) 'La estrategia de la oferta en la sociedad neocapitalista de consumo: Génesis y praxis de la investigación motivacional de la demanda', Política y Sociedad, 16: 37-92.

Ortí, A., (2012) "IN MEMORIAM: ÁNGEL DE LUCAS O LA HONESTIDAD DEL SABER SOCIOLÓGICO”, Sociología Histórica, 1: 251-279.

RAMOS, R. (1983) 'Informe-resumen de los resultados de una investigación sociológica sobre el aborto mediante discusiones de grupo', CIS (en línea: 16-10-2014: http:// www.reis.cis.es/REIS/PDF/REIS_021_13.pdf).

RICOEUR, P. (1974) "Psicoanálisis y Cultura", VVAA, Sociología contra Psicoanálisis. Barcelona, Martínez Roca.

RICOEUR, P. (1975) Hermenéutica y Estructuralismo. Buenos Aires, Megápolis.

RICOEUR, P. (1978) 'Imagen y lenguaje en psicoanálisis', Ricoeur, P. Escritos y conferencias 1. En torno al psicoanálisis. Madrid, Trotta, 2013.

RICOEUR, P. (1989) Ideología y utopía. Barcelona, Gedisa.

RICOEUR, P. (1995) Teoría de la interpretación. Discurso y excedente de sentido. Mexico, Siglo XXI.

ROSSI-LANDI, F. (1980) Significato, comunicazione e parlare comune. Venezia, Marsilio.

RUIZ RUIZ, J. (2009) 'Análisis sociológico del discurso: métodos y lógicas', Forum: Qualitative Social Research, 10 (2): art. 26.

RUIZ RUIZ, J. (2014) 'El discurso implícito: aportaciones para un análisis sociológico', Revista Española de Investigaciones Sociológicas, 146: 171-190.

SAUSSURE DE, F., (1916) Curso de lingüística general. Buenos Aires, Losada, 1945.

SOLMS, M. (2004) 'Preliminaries for an integration of psychoanalysis and neuroscience', Leuzinger-Bohleber, M., Dreher A.U. y Canestri, J (ed.) Pluralism and unity? Methods of Research in Psychoanalysis. London, International Psychoanalytic Association.

SPERBER, D Y WILSON, D. (1995) Relevance: communication and cognition. Oxford, Blackwell.

THERBORN, G. (1980) La Ideología del poder y el poder de la ideología. Madrid, Siglo XXI, 1987.

VAN DIJK, T. (1980) Texto y contexto. Semántica y pragmática del discurso. Madrid, Cátedra.

VAN DIJK, T. (1998) ‘UUn estudio lingüístico de la ideología?’, Parodi Sweis, G. (ed.) Discurso, cognición y educación. Ensayos en honor a Luis Gómez Macker. Valparaíso, Ediciones Universitarias de Valparaíso.

VAN DIJK, T. (comp.) (2000) Estudios sobre el discurso: una introducción multidisciplinaria. Barcelona, Gedisa.

VAN DIJK, T. (2003a) Ideología y Discurso. Barcelona, Ariel. 
VAN DIJK, T. (2003b) 'La multidisciplinariedad del análisis crítico del discurso: un alegato a favor de la diversidad', Wodak, R. y Meyer, M. Métodos de análisis del discurso. Barcelona, Gedisa.

VAN DIJK, T. (2012) Discurso y Contexto. Un análisis sociocognitivo. Barcelona, Gedisa.

VERÓN, E. (1976) El proceso ideológico. Buenos Aires, Tiempo Contemporáneo.

VOLOSHINOV, V. N. (1929) El marxismo y la filosofía del lenguaje. (Los principales problemas del método sociológico en las ciencias del lenguaje). Madrid, Alianza Editorial, 1992.

WILDEN, A. (1979) Sistema y estructura. Madrid, Alianza editorial.

WODAK, R. Y MEYER, M. (2003) Métodos de análisis del discurso. Barcelona, Gedisa. 